\title{
The Career Outcomes of Health Services and Policy Research Doctoral Graduates
}

\section{Perspectives de carrière pour les titulaires d'un doctorat en recherche sur les politiques et les services de santé}

\author{
ज्ञ \\ MEGHAN MCMAHON, MSC, PHD \\ Associate Director, CIHR Institute of Health Services and Policy Research \\ Institute of Health Policy, Management and Evaluation \\ University of Toronto \\ Toronto, ON \\ BETTINA HABIB, MSC, MSCPH \\ Research Assistant, Clinical and Health Informatics Research Group \\ McGill University \\ Montreal, QC \\ ROBYN TAMBLYN, PHD \\ Professor, Department of Medicine and Department of Epidemiology, \\ Biostatistics and Occupational Health \\ McGill University \\ Scientific Director (former), CIHR Institute of Health Services and Policy Research \\ Montreal, QC
}

\begin{abstract}
Objective: To examine the career outcomes of 20 years of $\mathrm{PhD}$ graduates from Canadian health services and policy research (HSPR) doctoral training programs.

Methods: The deans of the doctoral training programs were invited to participate in this national cohort study. A standardized career-tracking template was developed. Internet searches of publicly accessible sources were used to track graduates' employment. Descriptive analyses summarized $\mathrm{PhD}$ program characteristics and current employment.

Results: Of the 1,208 trainees who graduated during our study period, 884 (73.2\% of
\end{abstract}


1,208, or $90.3 \%$ of the 979 with complete data) could be successfully tracked. HSPR PhD graduates are highly employable, but employment trends have changed over time. Today's graduates are more likely to enter careers in a wider variety of sectors and roles and are less likely to be employed in academia than previous graduates. However, over $50 \%$ of graduates are currently employed in professorial positions within the academic sector or in research roles or departments within healthcare delivery organizations.

Conclusions: This article provides an initial descriptive profile of the career outcomes of HSPR PhD graduates in Canada from 10 university-based doctoral training programs. To ensure that $\mathrm{PhD}$ graduates are prepared to contribute fully within diverse sectors and roles, doctoral training must evolve to keep pace with employment trends and encompass, in addition to research skills, the professional skills demanded in the public, private, not-for-profit and healthcare delivery sectors.

\section{Résumé}

Objectifs : Examiner les perspectives de carrière, sur 20 ans, pour les titulaires d'un doctorat issu d'un programme canadien en recherche sur les politiques et les services de santé (RPSS). Méthode: Nous avons invité les doyens des programmes de doctorat à participer à cette étude de cohortes à l'échelle nationale. Nous avons mis au point un modèle normalisé pour suivre les parcours de carrière. Des recherches menées dans des sources publiques accessibles sur Internet ont permis de suivre les parcours des titulaires. L'analyse descriptive a permis de résumer les caractéristiques des programmes de doctorat ainsi que l'état actuel de l'embauche. Résultats: Parmi les 1208 doctorants qui ont obtenu leur diplôme au cours de la période visée par l'étude, on a pu suivre le parcours de 884 titulaires (73,2 \% de 1208 ou 90,3\% des 979 sujets pour qui les données sont complètes). Les titulaires d'un doctorat en RPSS sont hautement employables, mais les tendances du marché de l'emploi ont changé avec le temps. Les titulaires d'aujourd'hui ont davantage de chances de commencer une carrière dans une variété de secteurs et de postes et sont moins susceptibles d'être employés en milieu universitaire, comparativement aux titulaires antérieurs. Cependant, plus de $50 \%$ des titulaires occupent actuellement un poste professionnel dans un milieu universitaire ou dans un service ou poste de recherche au sein d'une organisation de prestation de services de santé.

Conclusion: Cet article apporte une première description des perspectives de carrière pour les titulaires d'un doctorat en RPSS issu d'un programme de formation doctorale dans 10 universités au Canada. Pour s'assurer que les titulaires d'un doctorat soient en mesure d'apporter leur entière contribution dans divers secteurs et postes, la formation doctorale doit évoluer afin de répondre aux tendances du marché de l'emploi et doit comprendre - en plus des compétences en recherche - les compétences professionnelles qui sont en demande dans les secteurs public, privé, à but non lucratif et de la santé. 


\section{Background}

The healthcare landscape in Canada is evolving. The multitude of complex challenges and the financial pressures confronting health systems are not new. But as governments and health service delivery and other organizations experiment with new ways of organizing, funding and delivering high-value care, they are beginning to invest in people and data to help understand which interventions work and to dynamically modify, adapt and innovate based on evidence. A range of health system and related organizations in Canada - including hospitals, ministries of health, health authorities, health charities, health technology companies and consulting firms - now have embedded research and/or quality improvement units and are employing health services and policy researchers in a variety of roles (Chafe and Dobrow 2008; Lomas and Brown 2009). As the concept of the learning health system (LHS) spreads - where organizations combine research, data science and quality improvement to continuously learn and improve outcomes (IOM 2013) - there will be a critical need for research leadership embedded within health system organizations to experiment with innovation, spearhead the adoption of evidence-informed successes and drive continuous improvement (Bindman 2017; Forrest et al. 2018; Psek et al. 2015; Reid 2016; Rich and Collins 2018; Tamblyn et al. 2016). This evolving landscape creates exciting opportunities for $\mathrm{PhD}$ graduates in health services and policy research (HSPR), who have received extensive academic training in the research techniques and evaluative methodologies required to analyze complex challenges and test innovations, to pursue impactful careers outside of the academy.

Alongside the heightened research capacity needs of health system organizations, there has been a decline in the number of tenure-track professor positions in universities relative to the number of PhD graduates. This trend is evident in Canada, in the US and across Europe (Porter et al. 2017). Although most doctoral programs were principally designed to prepare trainees for academic careers, with the traditional university professor role viewed as the pinnacle of success (Sinche et al. 2017), recent data from Canada indicate that only about $19 \%$ (Edge and Munro 2015) to 30\% (University of Toronto 2016) of graduates (in all disciplines) find employment in tenure-track professor positions. In the US, some universities report that approximately $40 \%$ of their $\mathrm{PhD}$ graduates are employed in tenure-track positions (examples include Cornell University [2018] and Princeton University [2019]). Overall, however, the majority of $\mathrm{PhD}$ graduates, ranging from 60 to $80 \%$ depending on the study, have entered careers in other roles and sectors.

In Canada, there has been mounting attention to modernizing HSPR doctoral programs to better prepare $\mathrm{PhD}$ graduates for stronger career readiness and greater impact in a wider variety of sectors and roles, within and beyond the academy. In addition to the demand from health system organizations for research talent in their teams, the excitement about the LHS and the career trends of $\mathrm{PhD}$ graduates, Canada's prioritization of HSPR training modernization also stems from demand from $\mathrm{PhD}$ trainees themselves. For many HSPR trainees, a traditional academic career is no longer the primary end goal (IHSPR 2017, 2019; Morrison 
et al. 2008). Instead, trainees want to contribute their skills at the coalface of health policy and delivery - in hospital settings, regional health authorities, health charities, tech firms and other arenas - where they can make an impact by leading evidence-informed innovation and health system improvement. However, their doctoral training was not designed with this end goal in mind. Trainees receive limited information about alternative career possibilities, little to no formal training in many of the competencies demanded in the non-academic labour market, such as leadership and project management, and few formal opportunities to apply and adapt their PhD skills within health system organizations (IHSPR 2016). To optimize investments in doctoral training for future career preparedness, it is essential to ensure that trainees are equipped with the skills, experiential learning opportunities and networks to make health, societal and economic contributions in a variety of sectors.

The Canadian Health Services and Policy Research Alliance's (CHSPRA) HSPR Training Modernization Strategy (2015) provided a catalyst for HSPR doctoral training programs, health system organizations, research funders and trainees to come together to identify strategies to train the next generation of research-skilled health system leaders. But very little is known about the career outcomes of past HSPR PhD graduates, in particular about the sectors in which they work, the positions they hold and the contributions they make in these careers. Understanding the career outcomes of past HSPR PhD graduates is important for informing training modernization endeavours, for helping pre-doctoral and doctoral trainees make informed career choices and for improving the evidence base regarding the breadth of societal impact that graduates are making by way of their career choices.

The dearth of information about $\mathrm{PhD}$ employment outcomes is not unique to the field of HSPR or to Canada (Benderly 2018). The statistic that $80 \%$ of $\mathrm{PhD}$ graduates work outside of traditional academic careers (Edge and Munro 2015) is often emphasized in discussions and presentations about $\mathrm{PhD}$ career transitions and outcomes; however, very little is known about this $80 \%$. Both the Canadian Council of Academies (2019) and the National Academy of Sciences, National Academy of Engineering, and Institute of Medicine (2014, 2018) in the US have signalled the importance of an improved understanding of labour market transitions and outcomes of PhD graduates. In an effort to address this information gap, universities and other higher education organizations have started to track $\mathrm{PhD}$ employment outcomes (Cornell University 2018; Duke University 2018; Jonker 2016; Porter et al. 2017; Princeton University 2019; Stanford University n.d.; University of Toronto 2016). These studies, which focus on $\mathrm{PhD}$ graduates from all faculties and disciplines within a university or province, have revealed that $\mathrm{PhD}$ graduates are highly employable and transition to careers in a variety of sectors, within and outside of academia (Jonker 2016; Porter et al. 2017; Stanford University n.d.; University of Toronto 2016). These studies, which harness publicly available information on the Internet to track career outcomes, provide a valuable starting point for the first-ever national cohort study of the employment outcomes of Canadian HSPR PhD graduates. 
The objective of the present project was to improve the evidence base regarding the career outcomes of 20 years of $\mathrm{PhD}$ graduates from Canadian HSPR and related doctoral training programs. The article provides an initial descriptive profile of the career outcomes of HSPR PhD graduates in Canada from 10 university training programs across the country. It is a core project of CHSPRA's Training Modernization Working Group and of the Canadian Institutes of Health Research's Institute of Health Services and Policy Research (CIHR-IHSPR).

\section{Methods}

The methods build on data collection approaches tested and used by the leaders of the University of Toronto's 10,000 PhDs Project and other PhD career outcomes studies (Jonker 2016; Porter et al. 2017; Stanford University n.d.; University of Toronto 2016). These studies relied on social media and other online sources of publicly accessible information to track graduates' employment outcomes, an approach that has been adopted in the present study. No contact with any graduate was made.

The deans and directors of 23 of Canada's HSPR and related doctoral training programs received a letter of invitation to participate in this national cohort study of $\mathrm{PhD}$ graduates' career outcomes, which outlined the project's objectives, inquired about their interest in participating, and committed to reporting back program-specific dashboards and raw data files. ${ }^{1}$ Programs that expressed an interest were sent a data collection template requesting preliminary information about their graduates that would be used to track career trajectories including name, $\mathrm{PhD}$ start and graduation date, thesis title, university department, program stream if relevant, and thesis supervisor.

A standardized career-tracking template and corresponding codebook that defined each variable were developed, informed by the work of the University of Toronto's 10,000 PhDs Project (University of Toronto 2016). An HSPR-specific categorization scheme for employment sectors, subsectors and roles was used (Bornstein et al. 2018) that included the following seven key sectors: academic, public, healthcare delivery, healthcare delivery research, private, not-for-profit and other (Table 1). When relevant, the first employment position after $\mathrm{PhD}$ graduation; the current primary, secondary and tertiary employment positions (e.g., physician and adjunct professor); and up to five primary employment positions in between were documented. For each employment position, the job title, name and geographical location of the organization and the organization's employment sector and subsector were recorded. A reporting dashboard of key employment indicators was piloted with three of the participating programs, and their feedback was used to refine the final set of indicators, which included the:

- percentage of graduates who pursued a post-doctoral position (at any point, either as the first employment position after $\mathrm{PhD}$ graduation or as a subsequent employment position); 
+ percentage of graduates currently in university professorial positions (assistant professor, associate professor, professor, lecturer);

- current primary employment sector and subsector (see Bornstein et al. 2018);

- employment location of current academics (same university as $\mathrm{PhD}$; same province but different university; in Canada but different province; US; outside of North America); and

- first employment sector after PhD graduation versus current primary employment sector (to examine sector retention).

TABLE 1. General descriptive statistics

\begin{tabular}{|c|c|c|c|c|c|}
\hline School & $\begin{array}{l}\text { Number of } \\
\text { graduates* }\end{array}$ & $\begin{array}{l}\text { Female, } \\
\text { n }(\%)^{\S}\end{array}$ & $\begin{array}{l}\text { Number of } \\
\text { graduates } \\
\text { with } \\
\text { follow-up data }\end{array}$ & $\begin{array}{l}\text { Graduates } \\
\text { who } \\
\text { completed } \\
\text { post-doc, } \\
\text { n (\%) }\end{array}$ & $\begin{array}{l}\text { Graduates } \\
\text { who are } \\
\text { current } \\
\text { professors, } \\
\text { n (\%) }\end{array}$ \\
\hline All Schools & ।,208 & $639(65.3)$ & 884 & $170(19.2)$ & $375(42.4)$ \\
\hline$U$ of Montreal & 229 & - & 0 & - & - \\
\hline$\cup$ of $T$ DLSPH & 184 & $128(69.6)$ & 170 & $16(9.4)$ & $66(38.8)$ \\
\hline$\cup$ of $T$ IHPME & 183 & $123(67.2)$ & 180 & $15(8.3)$ & $64(35.6)$ \\
\hline McGill & 169 & $107(63.3)$ & 150 & $45(30.0)$ & $66(44.0)$ \\
\hline McMaster & 127 & $70(55.1)$ & 112 & $21(18.8)$ & $44(39.3)$ \\
\hline UBC & 125 & $79(63.2)$ & 107 & $42(39.3)$ & $52(48.6)$ \\
\hline Waterloo & 72 & $48(66.7)$ & 64 & $14(2 \mid .9)$ & $34(53.1)$ \\
\hline$\cup$ of Manitoba & 56 & $4 \mid(73.2)$ & 47 & $3(6.4)$ & $29(61.7)$ \\
\hline Western & 53 & $35(66.0)$ & 45 & $10(22.2)$ & $19(42.2)$ \\
\hline Queen's & 10 & $8(80.0)$ & 9 & $4(44.4)$ & I (II.I) \\
\hline
\end{tabular}

*Variation in the number of graduates across programs reflects a combination of factors, including program size and program longevity.

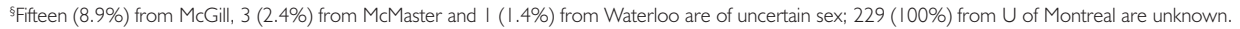

To track graduates, Internet searches of publicly accessible sources were used to collect employment data. The graduates' first and last names were the primary variables used to identify and track them, and their PhD start and graduation dates, thesis title, university and/or program and/or thesis supervisor's name were used to validate the match. The primary sources of data were university and employer websites, followed by LinkedIn. Additional data sources, if needed, included Google+, ResearchGate, Twitter and Facebook. A data analyst with expertise from the 10,000 $\mathrm{PhDs}$ Project completed all data collection between January and August 2018. A second member of the team validated the employment sector and subsector categorization. Program-specific data files were merged to create a pan-Canadian data file. 
Descriptive analyses were used to summarize $\mathrm{PhD}$ program characteristics and career trajectories for all graduates, as well as by graduation cohort (1996-1999, 2000-2004, 2005-2009, 2010-2014, 2015-2016), gender and program. All analyses were conducted in $\mathrm{R}$, and figures were created in Excel.

\section{Results}

Overall, nine of the $23 \mathrm{HSPR} \mathrm{PhD}$ training programs provided complete data on their graduates between 1996 and 2016, a 10th program provided partial data (but not the names of its graduates) and an 11th program was included because of the availability of the university's publicly accessible dissertation database that provided graduates' names. Three programs expressed interest but were unable to participate as they were newly established and had not yet graduated students. Three programs opted not to participate. Seven programs did not respond. The 11 programs included in the analysis collectively graduated $1,208 \mathrm{PhDs}$ between 1996 and 2016. Of these 1,208 graduates, names were provided for 979, and these individuals were included in the career-tracking analysis.

Of the 1,208 trainees who graduated during our study period, 884 (73.2\% of 1,208, or $90.3 \%$ of the 979 with nominal data) could be successfully tracked through social media (see Table 1). Sixty-five per cent were female, 19.2\% completed a post-doctoral fellowship and $37.3 \%$ currently hold professorial posts within academic institutions. University of Manitoba graduates were least likely to complete post-doctoral training but most likely to hold professorial positions in academic institutions relative to the other programs. The proportion of graduates who completed post-doctoral training increased from $10.2 \%$ for the 49 individuals who graduated between 1996 and 1999 to $36.5 \%$ for the 148 individuals who graduated between 2015 and 2016.

Among the $884 \mathrm{PhD}$ students who could be tracked, $47.5 \%$ were employed in academia at the time of tracking (January-August 2018), mainly as assistant, associate or full professors (Table 2). ${ }^{2}$ Male graduates (51.0\%) were more likely to be in academia than females (45.9\%) and were more likely to be employed in a professorial post within academia (41.9\% males versus $35.4 \%$ females). Employment in the healthcare delivery research sector (13.8\%) was the next most common career location, particularly for females (14.2\%), followed by the public sector in health-related fields (11.1\%). Although only a small proportion of graduates were employed in the private sector in 2016 (6.1\%), male graduates ( $8.1 \%)$ were more likely to be in these locations than females (4.5\%). Overall, more than $50 \%$ of graduates were employed in professorial positions within the academic sector or in research-related positions within the healthcare delivery research sector in 2018. 
The Career Outcomes of Health Services and Policy Research Doctoral Graduates

TABLE 2. Current employment sector and subsector, by sex

\begin{tabular}{|c|c|c|c|}
\hline & $\begin{array}{l}\text { Overall, } \\
\text { N (\%) } \\
884\end{array}$ & $\begin{array}{l}\text { Females, } \\
\text { n (\%) } \\
577\end{array}$ & $\begin{array}{l}\text { Males, } \\
\text { n (\%) } \\
298\end{array}$ \\
\hline Continued Training & $38(4.3)$ & $28(4.9)$ & $10(3.4)$ \\
\hline Post-doctoral fellow & $38(4.3)$ & $28(4.9)$ & $10(3.4)$ \\
\hline Academic Sector & $420(47.5)$ & $265(45.9)$ & $152(5 \mid .0)$ \\
\hline University professor* & $330(37.3)$ & $204(35.4)$ & $125(4 \mid .9)$ \\
\hline Research associate/assistant & $21(4.3)$ & $17(2.9)$ & $3(1.0)$ \\
\hline Administration & $16(1.8)$ & $10(1.7)$ & $5(1.7)$ \\
\hline College lecturer & $4(0.5)$ & $3(0.5)$ & I (0.3) \\
\hline Other (status, adjunct) & $49(5.5)$ & $31(5.4)$ & $18(6.0)$ \\
\hline Public Sector & $98(11.1)$ & $73(12.7)$ & $23(7.7)$ \\
\hline Broader public sector - health & $61(6.9)$ & $45(7.8)$ & $15(5.0)$ \\
\hline Government - health & $30(3.4)$ & $22(3.8)$ & $7(2.4)$ \\
\hline Broader public sector - non-health & $3(0.3)$ & $3(0.5)$ & $0(0.0)$ \\
\hline Government - other/non-health & $4(0.5)$ & $3(0.5)$ & I (0.0) \\
\hline Healthcare Delivery Sector & $62(7.0)$ & $38(6.6)$ & $24(8.1)$ \\
\hline Hospital & $48(5.4)$ & $26(4.5)$ & $22(7.4)$ \\
\hline Primary and community-based care & $12(1.4)$ & $10(1.7)$ & $2(0.7)$ \\
\hline Other & $2(0.2)$ & $2(0.4)$ & $0(0.0)$ \\
\hline Healthcare Delivery (Research) Sector & $122(13.8)$ & $82(14.2)$ & $40(13.4)$ \\
\hline Hospital (research) & $90(10.2)$ & $60(10.4)$ & $30(10.1)$ \\
\hline Research scientist/associate/assistant & $31(3.5)$ & $22(3.8)$ & $9(3.0)$ \\
\hline Primary and community-based care (research) & I $(0.1)$ & $0(0.0)$ & I (0.3) \\
\hline Private Sector & $54(6.1)$ & $26(4.5)$ & $24(8.1)$ \\
\hline Biotechnology/Pharmaceuticals & $26(2.9)$ & $16(2.8)$ & $8(2.7)$ \\
\hline Consulting & $12(1.4)$ & $3(0.5)$ & $9(3.0)$ \\
\hline Other (Ttechnology) & $7(0.8)$ & $2(0.4)$ & $4(1.3)$ \\
\hline Other & $9(1.0)$ & $5(0.9)$ & $3(1.0)$ \\
\hline
\end{tabular}


TABLE 2. Current employment sector and subsector, by sex (cont'd)

\begin{tabular}{|c|c|c|c|}
\hline & $\begin{array}{l}\text { Overall, } \\
\text { N (\%) } \\
884\end{array}$ & $\begin{array}{l}\text { Females, } \\
\text { n (\%) } \\
\mathbf{5 7 7}\end{array}$ & $\begin{array}{l}\text { Males, } \\
\text { n (\%) } \\
298\end{array}$ \\
\hline Not-for-Profit Sector & $49(5.5)$ & $35(6.1)$ & $14(4.7)$ \\
\hline Research and Ppublic Ppolicy & $24(2.7)$ & $17(2.9)$ & $7(2.3)$ \\
\hline Pan-Canadian Hhealth Oorganization & $9(1.0)$ & $7(1.2)$ & $2(0.7)$ \\
\hline Health Ccharity & $7(0.8)$ & $6(1.0)$ & I (0.3) \\
\hline Other (Hhealth- Rrelated) & $9(1.0)$ & $5(0.9)$ & $4(1.3)$ \\
\hline Other Sector & $41(4.6)$ & $30(5.2)$ & II (3.7) \\
\hline Consulting & II (1.2) & $10(1.7)$ & I (0.3) \\
\hline International Aagency (Hhealth Rrelated) & $12(1.4)$ & $7(1.2)$ & $5(1.7)$ \\
\hline Independent Bbusiness/Sself-Eemployed & $7(0.8)$ & $5(0.9)$ & $2(0.7)$ \\
\hline Retired & $4(0.5)$ & $2(0.4)$ & $2(0.7)$ \\
\hline Other/Unknown & $7(0.8)$ & $6(1.0)$ & I $(0.3)$ \\
\hline
\end{tabular}

*University professor was defined to include assistant/associate/professor/lecturer. In a sensitivity analysis, we excluded "lecturer" and the number and percentage of university professors changed to 320 (36.2\%).

Notes: (1) The employment sector is unknown for 95 graduates: 62 females and 23 males (besides the 229 unknown from $U$ of Montreal). (2) Among those whose sector is known, sex is uncertain for 9 graduates.

Current employment sector has changed through time (Figure 1 and Box 1). Compared to the 49 individuals who graduated between 1996 and 1999 (of whom 71.4\% were employed in academic settings in 2016), a decreasing number of graduates in subsequent years were employed in academia in 2016. Among graduates between 2010 and 2014, 45.3\% were employed in academia in 2016 - 38.7\% for those graduating after 2014. Over the 20-year study period, the main sectors that have seen an increase in employment of $\mathrm{PhD}$ trained graduates are the public sector (from $4.1 \%$ of individuals who graduated between 1996 and 1999 to $17.9 \%$ of those who graduated after 2014) and the healthcare delivery research sector (from $4.1 \%$ of the 1996-1999 graduating cohort to $15.1 \%$ of the post-2014 graduating cohort).

\section{BOX I. Changing employment trends}

Less than 30\% of HSPR graduates from the 1996-1999 cohort are currently employed outside of academia, whereas more than $60 \%$ of HSPR graduates from the 20 I 5-2016 cohort are currently employed outside of academia. Current graduates (i.e., 2015-2016 cohort) are more likely than previous graduates to work in research departments within healthcare delivery organizations (including academic teaching hospitals) and the public sector. 
FIGURE 1. Current employment sector, by cohort (graduation year)

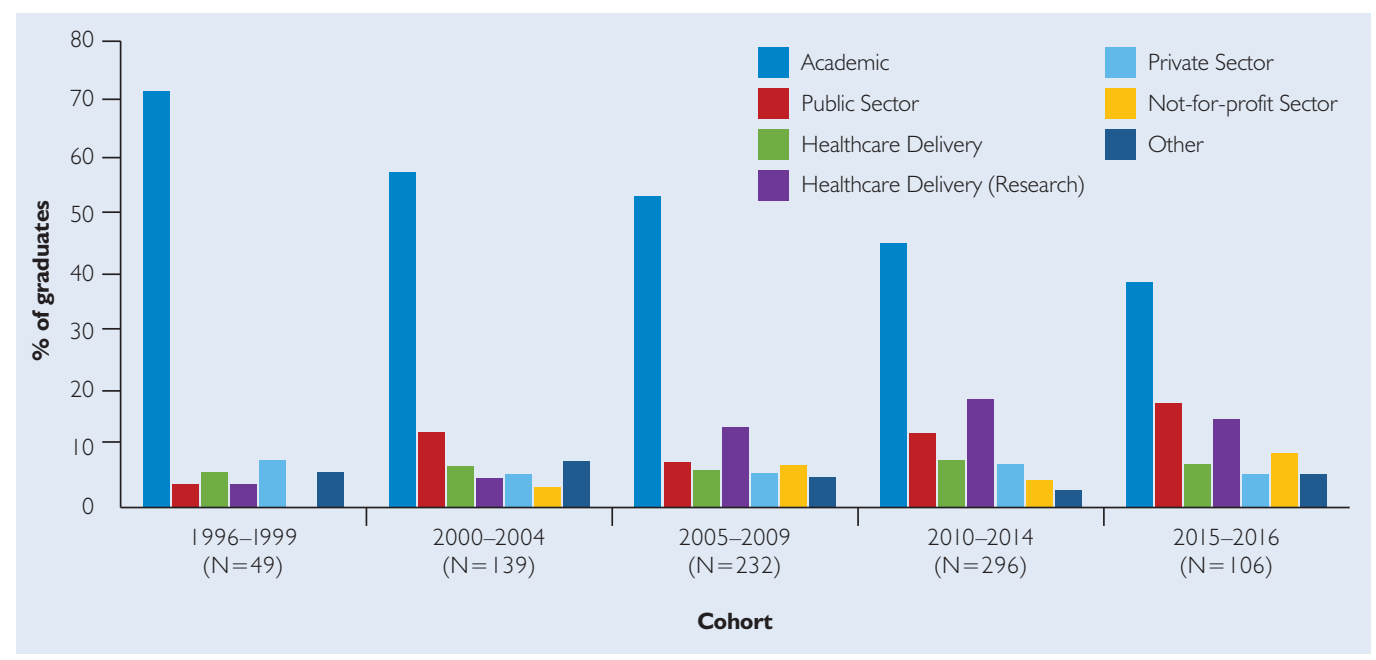

Results presented are based on data from $822(68 \%)$ graduates, excluding the 5 graduates whose graduation year is unknown and the 57 graduates whose current position is a post-doctorate fellowship ( 15 from cohort 2010-2014, 42 from cohort 2015-current).

Among the 457 (51.7\%) graduates whose first post-PhD employment sector and current employment in 2016 could be tracked, 67.8\% were working in the same sector as when they completed their PhD (Table 3, available online at longwoods.com/content/25982). Those first employed in academia (77.2\%) and the private sector (79.2\%) were most likely to remain in the same employment sector. Those first employed in not-for-profit agencies were the least likely to remain employed in this sector (45.0\%), primarily moving on to academia $(22.5 \%)$ or the public sector (12.5\%). In 2016, most graduates were employed in Canada (83.1\%), with a slightly higher proportion of female graduates (85.5\%) than male graduates $(78.4 \%)$.

Among the 293 female and 162 male graduates currently employed in academia, 36.9\% of female graduates and $35.2 \%$ of male graduates were employed in the same university in which they completed their $\mathrm{PhD}$. This varied by university, from 17.4 to $70.8 \%$, although the sample size in some programs is small and the proportions may be unreliable. Interestingly, male graduates were more likely to be employed in academic positions outside of Canada (24.1\%) compared to females (14.3\%).

Overall, Canada's HSPR PhD graduates are highly successful in finding employment in a variety of sectors, including academia, the public sector, the healthcare delivery sector, the private

BOX 2. Where are Canada's health services and policy PhD graduates working and in what types of roles?

Examples of the kinds of organizations where Canada's HSPR graduates are employed include: ministries of health, provincial health authorities, technology assessment agencies, public health units, health quality councils, academic teaching and community hospitals and their embedded research units, research funding organizations, federal agencies, health charities, international organizations, pharmaceutical companies, consulting firms, universities and more.

Examples of current employment roles include: associate medical officer, vice president of research, chief scientist, data scientist, director of research/health economics/ knowledge synthesis/surveillance, senior economist, president and CEO, global director, partner, professor, epidemiologist, scientist, post-doctoral fellow and more. 
sector, the not-for-Profit sector and the independent sector (i.e., self-employed, independent business). They work primarily in Canada but in 38 countries overall (including Canada). They are working and contributing their expertise in over 350 distinct organizations (Box 2). Within these organizations, $\mathrm{PhD}$ graduates have a variety of job titles and occupations, typically within a science-related role (see Box 2). Within the academic sector, $\mathrm{PhD}$ graduates are working in 115 universities in Canada and elsewhere. Their HSPR skills are in demand by many different faculties and departments, as evidenced by employment in faculties/schools/ departments of public health, medicine, pharmacy, health policy, nursing, health science, epidemiology, community health sciences and more.

\section{Discussion}

The present study examined the employment outcomes of $\mathrm{PhD}$ graduates from 10 Canadian HSPR doctoral training programs who completed their PhD between 1996 and 2016. It provides a comprehensive and first-ever profile of the careers of HSPR PhD graduates in Canada, including the sectors, subsectors, occupations and locations in which they currently work. The discussion that follows focuses on the main HSPR employment trends and how they compare to broader $\mathrm{PhD}$ employment trends and offers suggestions regarding the implications for doctoral training.

The study found that HSPR PhD graduates are highly employable but that employment trends have changed over time. Today's graduates are more likely than before to enter careers in a wider variety of sectors and occupations and are less likely to be employed in academia than previous graduates. This is not an HSPR-specific trend but a wider phenomenon: the decline in employment of $\mathrm{PhD}$ graduates in academic tenure-track positions and the increase in employment in other sectors and occupations is ubiquitous across all fields in all universities that have tracked their PhD graduates' career outcomes over time (Porter et al. 2017; Stanford University n.d.; University of Toronto 2016). A 2013 study from the Organisation for Economic Co-operation and Development (OECD) examining the careers of doctorate holders in OECD countries showed that in the US, Belgium, Denmark and the Netherlands, at least one in three employed doctorate holders worked in the private sector and between 20 and 35\% worked in the public (government) and/or not-for-profit sectors (Auriol et al. 2013). The increasing diversification of career choices of $\mathrm{PhD}$ graduates raises exciting possibilities for the spread of innovation through all facets of society. It also raises important questions about the value of the doctoral degree and implications for doctoral training curricula.

Given employment trends, there has been some debate about the value of the doctoral degree. Some argue that there is an oversupply of $\mathrm{PhDs}$ and an underutilization of their skills and that doing a PhD is "a waste of time" ("The Disposable Academic" 2010). The expansion in PhD enrolment levels in many countries - between 2000 and 2009, the number of doctoral degrees awarded in OECD countries increased by 38\% (Auriol et al. 2013) - and the decline in tenure-track employment are often cited as evidence (Auriol 2010). This argument's underlying assumption is that the value of a doctoral degree is limited 
to the availability of jobs in the academic sector. Others counter that PhD-trained individuals are a crucial resource in the knowledge economy and that, as a highly qualified workforce, they are essential to ensuring innovation in all sectors of society (Auriol 2010; Auriol et al. 2013). Of note is the fact that, in both 2000 and 2009, Canada's share of $\mathrm{PhD}$ graduates as a percentage of the population was well below the OECD average, ranking 25th out of the 36 countries for which data were available. While other OECD countries invested in increasing their supply of PhD graduates between 1998 and 2009, the supply in Canada stagnated (Auriol 2010; Auriol et al. 2013). The expansion of Canada's HSPR PhD supply over the last decade with the establishment of new doctoral training programs ${ }^{3}$ and schools of public health is, therefore, encouraging, particularly given that healthcare is a knowledge-intensive industry that demands a highly skilled workforce (Wolfson 2011). Recent survey data from a sample of 21 different types of healthcare and related organizations (e.g., delivery organizations, life sciences companies, health technology and data analytics companies, payers and purchasers) in the US indicate that the demand for HSPR skills is expected to increase over the coming years owing to the changing healthcare context (Rich and Collins 2018). The strong interest expressed by health system organizations to host Health System Impact fellows is a promising indication of demand in Canada, but it will be important to monitor demand over time.

There is some evidence to indicate that whereas $\mathrm{PhD}$ graduates who enter the academic sector in professor positions feel prepared for their careers, those in careers outside the academy vary in their feeling of preparedness (Bornstein et al. 2018; Porter et al. 2017). In the consultations leading up to the creation of the pan-Canadian Training Modernization Strategy, PhD trainees spoke of feeling underprepared to effect change in their non-academic workplaces, and health system employers commented on the substantial differences between academic and non-academic workplace cultures (Bornstein et al. 2018). This is perhaps not surprising given that the HSPR doctoral curriculum in most Canadian universities remains geared toward an academic career. A 2016 environmental scan of the PhD curriculum in Canada's HSPR doctoral programs and a 2016 survey of the directors of these programs found that few programs enrich their research-focused course offerings with professional development or "transferrable skills" courses (e.g., leadership, project management) and none require an experiential learning component (IHSPR 2016). The survey also revealed a strong appetite to incorporate such training elements moving forward.

The HSPR career trends documented in the present study suggest the need for a broader scope of doctoral training and better preparation for increasingly diverse roles. To contribute fully within today's healthcare ecosystem and to be prepared to lead in the LHS, new research on core competencies suggests that in addition to research methods and data analytics, $\mathrm{PhD}$ graduates also need skills in leadership, change management and implementation (also referred to as improvement and implementation science), engagement (also called interdisciplinary collaboration), communication and management (Atkins 2018; Bornstein et al. 2018; Burgess et al. 2018; Forrest et al. 2018; Rich and Collins 2018). 
In Europe, greater attention to preparing doctoral trainees for careers in industry has led to the creation of innovative new programs that emphasize research, innovation and transferable skills (Doonan et al. 2018). Programs such as the European Union's Innovative Training Networks and the industrial doctorate through the Marie Skłodowska-Curie Actions provide support for academia-industry partnerships and opportunities for doctoral trainees to benefit from hands-on opportunities to innovate with industry and develop transferable skills (Doonan et al. 2018; European Commission 2018). In the US, HSPR-specific training programs, such as AcademyHealth's Delivery System Science Fellowship, have been developed to prepare doctorate holders for careers in delivery organizations (see McMahon et al. [2019] in this issue and Kanani et al. [2017] for details).

In Canada, the HSPR community is learning from these and other training innovations in Canada, including training platforms such as Quebec's Training Program in Transdisciplinary Research on Public Health Interventions (the 4P Program) (Paradis et al. 2017) and others that were created through the CIHR Strategic Training Initiative in Health Research (STIHR) and the Regional Training Centres that were funded through the Capacity for Applied and Developmental Research and Evaluation (CADRE) program (Conrad 2008; Martens 2008), and making a concerted effort to ensure that trainees and post-doctoral fellows are poised for success in academic, applied and hybrid careers. For example, the recently developed Health System Impact Fellowship program led by the CIHR-IHSPR and CHSPRA provides PhD trainees and post-doctoral fellows with the opportunity to work within health system and related organizations on impact-oriented projects of high priority to their host partner organization. Fellows are supervised and mentored by senior-level leaders in the organization and receive a dedicated training allowance to support their development of an enriched set of core competencies (see Bornstein et al. [2018] for details and McMahon et al. [2019] in this issue). Although the program is in its early days, $97 \%$ of the first cohort of fellows $(n=46)$ reported that the fellowship provided them with opportunities to develop their leadership skills, 92\% indicated that they had the opportunity to develop their change management and implementation skills and $97 \%$ had the opportunity to improve their understanding of health systems and policy-making processes. It is promising that the second launch of the program witnessed a $31 \%$ increase in application pressure to the post-doctoral stream and that demand from health system organizations to embed fellows is rising concomitantly. Although these are promising signs, the ultimate success of training modernization efforts will depend on the extent to which doctoral training programs embrace these modernized elements as core features of their curricula. All signs to date are promising.

Finally, the gender-specific trends in employment outcomes that this study observed are worthy of comment and further attention. The results indicate that women are less likely than men to have careers in the private sector, less likely to be in academia and less likely to be employed in academic positions outside of Canada. These gender trends have been 
observed in other $\mathrm{PhD}$ career outcomes studies too (Porter et al. 2017). An important area for future research is to understand the factors that drive these trends and whether there are systemic barriers in the labour market, gaps in doctoral training and supports, differences in career preferences or a combination of these and other factors that require policy attention.

\section{Limitations}

This project documented career outcomes, but it is not known whether outcomes align with graduates' underlying career preferences, whether career preferences have changed over time (and if so, why), the extent to which graduates are satisfied with their careers or whether and how doctoral training contributed to employment performance. A mixed-methods research study that includes interviews with graduates and their employers could examine important questions such as the following: Is the increasing employment in non-academic fields a reflection of increased desire to contribute in applied settings or a reflection of disillusionment with career prospects in academia? To what extent are HSPR doctoral holders using their research skills when employed outside of the academic sector? To what extent are HSPR doctorate holders satisfied in their careers? A recent survey of over 8,000 $\mathrm{PhD}$ graduates in a diverse array of fields from over 500 science-related $\mathrm{PhD}$ training programs in the US found that job satisfaction among graduates was high and not statistically different for those employed in research-intensive positions (including tenure-track research and industry and government research) and non-research-intensive positions (such as science policy, administration, business development, consulting and others) (Sinche et al. 2017). There is no evidence to indicate that the preferences or satisfaction among HSPR $\mathrm{PhD}$ graduates would differ, and it is not a stretch to imagine stronger preferences for careers outside of the university setting given the applied nature of the HSPR field. However, future research that examines, empirically, the career preferences and satisfaction of HSPR PhD graduates would be a valuble contribution to the evidence base in Canada.

Our project was based on data from a subset of Canada's HSPR PhD programs. It is unknown whether the employment outcomes of participating programs differ from those of non-participants, and the results should therefore be interpreted as directional in nature rather than definitive. However, most of the major hubs of HSPR training (based on grants and awards dollars [Sullivan and Associates 2014]) were included, and the findings are consistent with the results of other PhD career-tracking studies. The analysis relied on publicly available data sources, and it is not known whether the information retrieved is fully accurate. However, data that appeared to be potentially erroneous were checked with the training program (e.g., $\mathrm{PhD}$ completion times of one year) and updated if necessary. Finally, the original intent of the analysis was to track career trajectories, including employment transitions, over time. However, the publicly available online data contained too many gaps to accurately identify an individual's full career trajectory. Future research that couples Internet searches with surveys of $\mathrm{PhD}$ graduates could help address this gap. 


\section{Conclusions}

Employment trends for Canada's HSPR PhD graduates have changed over time and remain bright. Recent graduates are more likely to work in a variety of sectors, including but not limited to academia. That HSPR PhD graduates are employed in the public, private, not-for-profit, healthcare delivery and independent sectors in a variety of leadership and science-related roles is promising for the knowledge economy and societal innovation. It is notable that more than $50 \%$ of the HSPR PhD graduates who could be tracked are currently employed in professorial positions or in research-related roles (e.g., scientist, epidemiologist, research director) within healthcare delivery organizations, such as in academic teaching hospitals. However, to ensure that $\mathrm{PhD}$ graduates are prepared to contribute fully within diverse sectors and roles, doctoral training must evolve to keep pace with employment trends and encompass, in addition to research and analytic skills, the professional skills demanded in the public, private, not-for-profit and healthcare delivery sectors.

As doctoral training and research funding programs evolve, it will be important to replicate this initial project and assess whether and how career outcomes change. Future career outcomes studies may also benefit from incorporating key informant interviews or surveys of graduates to assess the factors driving career choices and to better understand employment satisfaction, job stability, self-perceived preparedness for their job and the contributions they make in their roles. It is hoped that the data collection tools developed for the present study will be a resource for doctoral training programs in Canada to incorporate tracking as a routine element of their impact assessment and that use of a common set of indicators, such as those used in this study, will enable comparisons across the country and over time.

\section{Notes}

1. The 23 HSPR training programs were identified using a list that CIHR-IHSPR compiled in 2016 (http://www.cihr-irsc.gc.ca/e/49884.html). It is possible that some programs were missed and that the list and outreach were comprehensive but not exhaustive.

2. To examine the sensitivity of our findings to how the "university professor" subsector variable was defined, we excluded "lecturer" and re-estimated our descriptive analyses. When "lecturer" is excluded and re-categorized as "other," $36.2 \%$, rather than $37.3 \%$, are employed in university professorial positions. The overall percentage of graduates employed in the academic sector $-47.5 \%$ - is unaffected.

3. New programs that have entered the market include, for example, McMaster University's PhD in Health Policy program in 2008, the University of Ottawa's Telfer School of Management's PhD in Health Systems and Dalhousie University's PhD in Epidemiology and Applied Health Research and PhD in Health programs in 2015. 


\section{Acknowledgements}

The authors would like to thank Dr. Reinhart Reithmeier for inspiring this career-tracking study and for sharing his methodology and insight from the 10,000 PhDs Project that he led at the University of Toronto. The authors thank Chang Zou for his help with data collection, without which this study would not have been possible. The authors would also like to thank the participating programs for their contributions to this first-ever profile of the career outcomes of HSPR PhD graduates in Canada.

Correspondence may be directed to: Meghan McMahon, PhD; e-mail: mmcmahon.ibspr@ices.on.ca.

\section{References}

Atkins, D. 2018. "Are We Growing the Right Health Services Research Workforce of the Future? Thoughts from a National Delivery System." Health Services Research 53(Suppl. 2): 54030-40. doi:10.1111/1475-6773.13032.

Auriol, L. 2010. “Careers of Doctorate Holders: Employment and Mobility Patterns." OECD Science, Technology and Industry Working Papers. No. 2010/04. Paris, France: OECD Publishing. Retrieved November 24, 2018. <http://dx.doi.org/10.1787/5kmh8phxvvf5-en>.

Auriol, L., M. Misu and R. Freeman. 2013. "Careers of Doctorate Holders: Analysis of Labour Market and Mobility Indicators." OECD Science, Technology and Industry Working Papers. No. 2013/04. Paris, France: OECD Publishing. Retrieved November 24, 2018. <http://dx.doi.org/10.1787/5k43nxgs289w-en>.

Benderly, B.L. 2018, March 7. "A Trend Toward Transparency for Ph.D. Career Outcomes?" Science. Retrieved November 24, 2018. <https://www.sciencemag.org/careers/2018/03/ trend-toward-transparency-phd-career-outcomes $>$.

Bindman, A.B. 2017. "The Agency for Healthcare Research and Quality and the Development of a Learning Health Care System." JAMA Internal Medicine 177(7): 909-10. doi:10.1001/jamainternmed.2017.2589.

Bornstein, S., M. Heritage, A. Chudak, R. Tamblyn, M. McMahon and A. Brown. 2018. “Development of Enriched Core Competencies for Health Services and Policy Research." Health Services Research 53(5 Suppl. 2): 4004-23. doi.org/10.1111/1475-6773.12847.

Burgess, J.F., N. Menachemi and M. Maciejewski. 2018. "Update on the Health Services Research Doctoral Core Competencies." Health Services Research 53(5 Suppl. 2): 3985-4003. doi:10.1111/1475-6773.12851.

Canadian Council of Academies. 2019. The Labour Market Transition of PhD Graduates. Retrieved August 7 , 2019. <https://cca-reports.ca/reports/the-labour-market-transition-of-phd-graduates/>.

Canadian Health Services and Policy Research Alliance Training Modernization Working Group. 2015.

Challenges, Opportunities, and Future Directions for Health Services and Policy Research in Canada: A White Paper. Ottawa, ON: Canadian Institutes of Health Research.

Chafe, R. and M. Dobrow. 2008. "Health Services Researchers Working within Healthcare Organizations: The Intriguing Sound of Three Hands Clapping." Healthcare Policy 4(2): 37-45.

Conrad, P. 2008. “To Boldly Go: A Partnership Enterprise to Produce Applied Health and Nursing Services Researchers in Canada." Healthcare Policy 3(Special Issue): 13-30. doi:10.12927/hcpol.2008.19810.

Cornell University. 2018. “Doctoral Career Outcomes.” Retrieved August 7, 2019. <https://gradschool.cornell. edu/degrees-fields/program-metrics-assessments-and-outcomes/doctoral-career-outcomes/>

Doonan, F., L. Taylor, P. Branduardi and J.P. Morrissey. 2018. "Innovative Training Networks: Overview of the Marie Skłodowska-Curie PhD Training Model.” FEMS Microbiology Letters 365(19). doi:10.1093/femsle/ fny207. 
Duke University. 2018. “All Departments: PhD Career Outcomes Statistics." Retrieved August 7, 2019. $<$ https:/gradschool.duke.edu/about/statistics/all-departments-phd-career-outcomes-statistics $>$.

Edge, J. and D. Munro. 2015. Inside and Outside the Academy: Valuing and Preparing PhDs for Careers. Ottawa, ON: Conference Board of Canada.

European Commission. 2018. Marie Skłodowska-Curie Actions: Research Networks. Retrieved November 25, 2018. <https://ec.europa.eu/research/mariecurieactions/actions/research-networks_en>.

Forrest, C.B., F.D. Chesley Jr., M.L. Tregear and K.B. Mistry. 2018. “Development of the Learning Health System Researcher Core Competencies." Health Services Research 53(4): 2615-32. doi:10.1111/1475-6773.12751.

Institute of Health Services and Policy Research (IHSPR). 2016. A Pan-Canadian Health Services and Policy Research Curriculum for Enriched Core Competencies: An Environmental Scan. Internal report.

Institute of Health Services and Policy Research (IHSPR). 2017. HSPR Community Engagement Survey: Informing the Training Modernization Funding Strategy. Internal document.

Institute of Health Services and Policy Research (IHSPR). 2019. Analysis of HSIF Enriched Core Competency Assessments. Internal document.

Institute of Medicine (IOM). 2013. Best Care at Lower Cost: The Path to Continuously Learning Health Care in America. Washington, DC: The National Academies Press.

Jonker, L. 2016. Ontario's PhD Graduates from 2009: Where Are They Now? Toronto, ON: Higher Education Quality Council of Ontario. Retrieved August 10, 2018. <http://www.heqco.ca/SiteCollectionDocuments/ Ontario\%27s-PhD-Graduates-from-2009-ENG.pdf>.

Kanani, N., E.E. Hahn, M.K. Gould, K.D. Brunisholz, L.A. Savitz and E.C. Holve. 2017. “AcademyHealth's Delivery System Science Fellowship: Training Embedded Researchers to Design, Implement, and Evaluate New Models of Care." Journal of Hospital Medicine 12(7): 570-74. doi:10.12788/jhm.2776.

Lomas, J. and A.D. Brown. 2009. "Research and Advice Giving: A Functional View of EvidenceInformed Policy Advice in a Canadian Ministry of Health." The Milbank Quarterly 87(4): 903-26. doi:10.1111/j.1468-0009.2009.00583.x.

Martens, P.J. 2008. “The Regional Training Centre: If We Build It [Well], They Will Come." Healthcare Policy 3(Special Issue): 7-12. doi:10.12927/hcpol.2008.19809.

McMahon, M., S. Bornstein, A. Brown, S. Simpson, L. Savitz and R. Tamblyn. 2019. "Training for Health System Improvement: Emerging Lessons from Canadian and US Approaches to Embedded Fellowships." Healthcare Policy 15(Special Issue): 34-48. doi:10.12927/hcpap.2019.25981.

Morrison, E., J. Thornhill and S. Sheps. 2008. “A Foot in Both Camps: Graduate Voices at the Interface of Applied Health Services Research, Policy and Decision-Making." Healthcare Policy 3(Special Issue): 118-30. doi:10.12927/hcpol.2008.19818.

National Academy of Sciences, National Academy of Engineering, and Institute of Medicine. 2014. The Postdoctoral Experience Revisited. Washington, DC: The National Academies Press.

National Academy of Sciences, National Academy of Engineering, and Institute of Medicine. 2018. The Next Generation of Biomedical and Behavioral Sciences Researchers: Breaking Through. Washington, DC: The National Academies Press.

Paradis, G., A.-M. Hamelin, M. Malowany, J. Levy, M. Rossignol, P. Bergeron et al. 2017. "The UniversityPublic Health Partnership for Public Health Research Training in Quebec, Canada." American Journal of Public Health 107(1): 100-04. doi:10.2105/AJPH.2016.303529.

Porter, S., L. Mol, J. Locher and M. Johnston. 2017. UBC PhD Career Outcomes: Graduates from 2005 to 2013 UBC Vancouver Campus. UBC Graduate \& Postdoctoral Studies. Retrieved November 22, 2018. <http:// outcomes.grad.ubc.ca/docs/UBC_PhD_Career_Outcomes_April2017.pdf >.

Princeton University. 2019. “Ph.D. Long-Term Career Outcomes." Retrieved August 7, 2019. <https:// gradschool.princeton.edu/about/statistics/phd-long-term-career-outcomes $>$.

Psek, W.A., R.A. Stametz, L.D. Bailey-Davis, D. Davis, J. Darer, W.A. Fawcett et al. 2015. “Operationalizing the Learning Health Care System in an Integrated Delivery System." eGEMs (Generating Evidence E Methods to Improve Patient Outcomes) 3(1): 1122. doi:10.13063/2327-9214.1122. 


\section{The Career Outcomes of Health Services and Policy Research Doctoral Graduates}

Reid, R.J. 2016. "Embedding Research in the Learning Health System." HealthcarePapers 16(Special Issue): 30-35. doi:10.12927/hcpap.2016.24724.

Rich, E. and A. Collins. 2018. "Current and Future Demand for Health Services Researchers:

Perspectives from Diverse Research Organizations." Health Services Research 53 (5 Suppl. 2): 3927-44.

doi:10.1111/1475-6773.12999.

Sinche, M., R.L. Layton, P.D. Brandt, A.B. O'Connell, J.D. Hall, A.M. Freeman et al. 2017. "An EvidenceBased Evaluation of Transferrable Skills and Job Satisfaction for Science PhDs." PLoS ONE 12(9):e0185023. doi:10.1371/journal.pone.0185023.

Stanford University (n.d.). "PhD Jobs: The Stanford PhD Alumni Employment Project." Retrieved August 8, 2018. <https://irds.stanford.edu/phd-jobs >.

Sullivan, T. and Associates. 2014. A Pan-Canadian Vision and Strategy for Health Services and Policy Research. Phase 1: Building the Foundation. Retrieved August 4, 2019. <http://www.cihr-irsc.gc.ca/e/47946.html\#tab_7>.

Tamblyn, R., M. McMahon, J. Nadigel, B. Dunning and E. Drake with the Institute of Health Services and Policy Research Advisory Board. 2016. "Health System Transformation Through Research Innovation." HealthcarePapers 16(Special Issue): 8-19. doi:10.12927/hcpap.2016.24719.

"The Disposable Academic." 2010, December 16. Retrieved November 25, 2018. <https://www.economist.com/ christmas-specials/2010/12/16/the-disposable-academic $>$.

University of Toronto. 2016. Employed and Engaged: An Overview of the 10,000 PhDs Project. Retrieved August 8, 2018. <http://www.sgs.utoronto.ca/Documents/SGS_Overview_10KPhDsProject.pdf>.

Wolfson, M. 2011. "Health Care Is a Knowledge Industry, and Should Be More So." In F. Gorbet and A. Sharpe, eds., New Directions for Intelligent Government in Canada: Papers in Honour of Ian Stewart. Ottawa, ON: Centre for the Study of Living Standards. Retrieved November 24, 2018. <http://www.csls.ca/festschrift/ StewartFestschrift.pdf\#page $=257>$. 